\title{
Language learning and learning strategy use in international university students' English as a lingua franca communication
}

\author{
Donald W. Peckham ${ }^{12}$ \\ University of Szeged
}

DOI: 10.14232/edulingua.2020.1.1

\begin{abstract}
English as a lingua franca (ELF) has received wide interest in the past decades from researchers, teachers, and users of English in general. The present study investigates whether or not speakers of English approach ELF contexts not only as contexts for communication, but also as contexts for language learning. Interview data was collected from 12 international university students in Czechia and Hungary to explore if indeed they believe they are using ELF communication for their own language learning, and if so, what learning strategies they use. Results show that these English speakers are indeed learning in these contexts and employ a variety of strategies to do so. Implications for how secondary school English language instruction might prepare students for learning while using English as a lingua franca are discussed.
\end{abstract}

Keywords: English as a lingua franca, language learning strategies, study abroad, English language teaching and learning

\section{Introduction}

Each year in the European Union, around 9.5\% of students in higher education are international students (OECD, 2020), including, in 2018, nearly 350,000 students participating in the Erasmus+ program (Directorate-General for Education, Youth, Sport and Culture, 2020, p. 32). Many of these students attend English-language medium undergraduate and graduate programs which attract a multinational and multilingual group of students (Wächter \& Maiworm, 2014). English may also be used to interact with fellow students outside of class, and in almost all cases, students will be using English as a lingua franca. For most of these programs, the focus is not on English language learning, but on learning academic content, and previous research on the use of English as a lingua franca (ELF) in these contexts has mainly focused on classroom interaction (e.g. Smit, 2010) or the development of a community of ELF users outside the classroom (e.g. Kalocsai, 2014). Little research has focused on English language

\footnotetext{
${ }^{1}$ Author's e-mail: peckham@lit.u-szeged.hu

${ }^{2}$ I would like to thank the two reviewers of this paper for their detailed and valuable feedback.
} 
learning itself in these situations. This paper will address English language learning in an EU study abroad program by raising the issue of whether students themselves engage in activities which can potentially lead to language learning through using ELF. That is, are students who are interacting with fellow students simply using their English skills and practicing them, or are they actively developing them? And furthermore, how does the context of doing this through ELF affect their approach to learning? This paper will add to the literature which highlights the importance of ELF interaction as a site of active language learning, an issue which is important for both English language teachers and learners.

\section{Literature Review}

ELF simply refers to the use of English in situations where non-native speakers are the major participants and norm setters (Jenkins, 2007). In the past 20 years, it has received a great amount of attention with the recognition early on that there are more non-native speakers of English in the world and that a large percentage of communication in English either involves non-native speakers or is exclusively between non-native speakers (Graddol, 2006). Issues had previously been raised concerning the "ownership" of English (Widdowson, 1994) which led to discussion about what the language norms for non-native speakers should be based on (Seidlhofer, 2000). In their review of the field, Jenkins, Dewey and Cogo (2011) note that early on a major effort was made to provide a coherent structural description of English as a lingua franca, but that this goal was not reached due to the large amount of structural variation found in ELF interaction. But efforts were much more fruitful in describing how ELF interaction takes place and what makes such interaction successful. This movement away from a structure description of ELF meant that emphasis was placed on how participants learn the communication practices of using ELF in short- or longer-term encounters.

In a recent discussion framing ELF, Mauranen (2018) describes ELF from three interrelated perspectives. From the macro, or sociolinguistic perspective, Mauranen notes that thinking of ELF as a particular variety is problematic because there is no one ELF speech community and that within a group there is great amount of variety present when ELF is used. Instead, she posits that ELF begins with "similects" (p. 9) which are developed when speakers of the same first language learn English as a foreign language; that is, similects are the result of contact between one common first language and English, and thus contain, among other things, various transfer features which would be expected from that first language. ELF, then, involves contact between speakers of different similects and thus is "a higher-order or second-order" language contact (p. 10). She notes that spaces where ELF communication happens range from ephemeral service exchanges to more long-lasting encounters such as in professional organizations or in the EU governing bodies, and that "In short, ELF communities are diffuse, networkbased multilingual communities where English is a dominant lingua franca" (p. 12). 


\section{EduLingua 6/1 (2020)}

There has been controversy over describing speakers in ELF interaction as "language learners" since this may imply an English as a foreign language learning perspective with native English goals, and, particularly as studied from the second language acquisition perspective, is seen to imply a "deficit" approach that focuses on speakers' divergence from native English norms (Ranta, 2018, p. 146). This, along with the sidelining of the goal to describe ELF as a variety, as mentioned above, led to scant focus on structural learning in ELF communication, but in recent years this question has been raised again in contexts where ELF is used as an academic lingua franca in higher education settings. Smit (2010), in her book-length discussion of the subject, points out that given their wide variety of backgrounds, ELF users may also be English language learners who engage in explicit learning: "Therefore, some participants might pursue the intention of improving their English language proficiency and unite in themselves the roles of (ELF) language user and of English language learner, be it for general or some specific purposes," (p. 69). Similarly, Kalocsai (2014) discusses in her monograph presenting the Erasmus students as a community of practice, that through ELF interaction, a goal of many of the students was improving their English skills and "gaining self-confidence in ELF" (p. 171). Furthermore, Mauranen (2018) also discusses specific processes by which participants in ELF interaction are learning. At the meso level, where interaction takes place, this involves accommodation and explication, that is, explaining and elaboration. At the individual cognitive level, this involves entrenchment, where the most frequent uses of forms become the one most likely to be learned, and abstraction, where rules and patterns emerge though the encountering of exemplars. Thus, this perspective on learning relates to usage-based views on language learning in the second language acquisition literature which claim that language learning emerges though language use (Ellis \& Larsen-Freeman, 2006). Thus, although speakers may see themselves as users of English, learning is also possible (Hynninen, 2016, p. 13).

While it is possible that learning does happen in ELF encounters, it is rather difficult to assess this learning in the short or long term. Given the fluid nature of ELF encounters as higher order language contact situations, it is unclear what standards could be used to measure this change in knowledge and skill. Increased fluency could be measured due to the proceduralization and automatization of whatever forms are known (see De Jong \& Perfetti, 2011), but it would be difficult to assess what new structures have been learned. A partial solution to this problem is using self-report data. This provides a weaker measure of what exactly has been learned but will provide an indication that learning of some kind is happening. In the present paper, two self-report measures will be used: reports on the language learning strategies of participants, and reports on perceptions of learning.

Concerning learning strategies, the goal of this present paper is not to classify students' behavior into groups of already existing strategies (such as Oxford 1990), but to establish from the bottom-up that they are indeed using strategies. Therefore, 
establishing a definition of learning strategies is important. Cohen and Henry (2020) offer a succinct definition that language learning strategies are "the conscious and semiconscious thoughts and behaviours used by learners with the explicit goal of improving their knowledge and understanding of a target language," (p. 169). This definition would certainly apply to language classrooms and self-study but appears too limited for learning through communication in ELF contexts where language use and learning are always linked. On the other hand, Oxford (2017) gives a more complex definition:

L2 learning strategies are complex, dynamic thoughts and actions, selected and used by learners with some degree of consciousness in specific contexts in order to regulate multiple aspects of themselves (such as cognitive, emotional, and social) for the purpose of (a) accomplishing language tasks; (b) improving language performance or use; and/or (c) enhancing long-term proficiency. (p. 48)

In this definition, learning and use are linked together and the definition is sensitive to a wider range of activities, contexts, and purposes. Furthermore, Pawlak and Oxford (2018) in an article looking at new directions for language learning strategy research, call for research in specific contexts, stating that "research into diverse influences on the use of strategies and the ways in which such use translates into learning outcomes would become more revealing if it were complemented by a situated, context-sensitive and dynamic dimension" (p. 529). Situations where ELF is used is one such dynamic and complex context.

It is also important to define what is meant by "learning" in this paper. Following a usage-based perspective learning is seen as establishing and developing the multitude of form-meaning "constructions" (Goldberg, 2006) which are the foundation of language. Here, the concept of construction, rather than grammar and lexis, is particularly suitable for investigating learning in ELF contexts. Even though exemplars are abstracted through experiencing multiple iterations of the same pairings of form and meaning, these constructions are inherently bound to communicative contexts (Bybee, 2010). Thus, learning refers to learning constructions on any level from words and phrases, and also may involve various levels from establishing a new form-meaning relationship and strengthening it through iteration, to the abstraction of an exemplar all of which may be described by participants themselves as learning "grammar and vocabulary".

This leads to the following research questions that this paper addresses: 1) Do participants in ELF interaction report learning which helps them to successfully participate in tasks, improve their skills, or develop their proficiency in the long term?; and, 2) What strategic learning behaviors do participants in ELF interaction engage in to successfully participate in tasks, improve their skills, or develop their proficiency in the long term? 


\section{Methodology}

Data for this paper is drawn from interviews with 12 Erasmus students studying abroad in Hungary and Czechia ${ }^{3}$. The learning strategy data from seven students whose data was representative of the larger group is presented below. Among the seven students, five were from Germany, and one each from Finland and France. The students came from a variety of backgrounds in the arts and sciences and were spending one or two semesters abroad. All participants had at least one month of experience studying abroad at the time of the data collection. Students in Prague were interviewed after their first semester abroad, and students in Szeged were interviewed during a summer Hungarian language course prior to their first semester abroad.

The data collection consisted of two parts: a communicative task which pairs of participants completed, and an immediately following retrospective interview with individuals. Both the task and interview components were recorded. For the communicative task, pairs of participants were asked to assemble a set of PowerPoint slides about the city they were studying in which could be used in a presentation to encourage other international students to study there. The purpose of the task, which consisted of choosing and arranging a set pictures and providing captions for them, was to prime participants for thinking about using ELF and to give them an immediate experience of using English with a fellow student to refer to. The interaction and negotiation between the two participants as they created their PowerPoint slides was recorded. Individual retrospective interviews were carried out following the task, and it is these interviews which form the data for this paper. During the interviews, a participant and researcher together listened to the recording of the just-completed task of organizing the PowerPoint slides, and participants were invited to comment on language related episodes (Jackson, 2001), that is points where participants were negotiating about, focusing on, or discussing language itself. Furthermore, during and after listening to the completed task, participants were asked to comment on their use of ELF and potential learning in the ELF context in general. The interviews lasted between one and one-and-half hours.

The data was transcribed and then analyzed using content analysis to collect participant comments around common themes concerning using and learning English in ELF contexts. The recorded interaction data between the participants was not analyzed for this present paper. From these themes and using the definition of learning strategies

\footnotetext{
${ }^{3}$ The data for this paper comes from a larger project on English as a lingua franca in Europe, which in turn was part of the EU-wide Languages in a Network of European Excellence (LINEE) research project which was carried out between 2006 and 2010 (funded by the European Commission's 6th Framework Program, FP6\# 028388). Data collection and transcription was done by Karolina Kalocsai, Emöke Kovács, and the author. Previously, some of this data was reported on in Jenkins et al. (2010) and published in Cogo and Jenkins (2010). The analysis of the data in this present paper is the author's and was first presented in Peckham (2009a).
} 
discussed in the literature review, several general learning strategies were isolated. It is important to note that this is a bottom-up analysis of the data done in order to see which strategies emerge. The data was not analyzed in terms of existing taxonomies of learning strategies. This is justified on two counts. First, there is a tendency in learning strategy research itself to move away from asking participants about the use of particular strategies, to asking participants if they have strategies that they use in particular situations or for certain functions (Tseng, Dörnyei, \& Schmitt, 2006). And second, the ELF context is one where very little strategy research has been done, and it is likely that the kinds of strategies that emerge will be highly dependent on these contexts. For example, see the "let it pass" strategy (Firth, 1996), which is probably unique to ELF contexts.

\section{Results and Discussion}

Prior to presenting the results, it should be mentioned that all of the ELF use that participants discussed in their interviews occurred outside of their academic classes. That is, no participants mentioned developments in their academic English; all discussions about interaction concerned out-of-class interaction in English. There can be two main reasons for this. First, not all students were using English as the medium of instruction in their classes in their study abroad program, and so their individual experiences may have been different. Second, and more importantly, the students we interviewed were using English in close social relationships with other international students and locals, and this is a hallmark of the collective experience of international students as has been shown in previous studies (Kalocsai, 2014; Peckham, Kalocsai, Kovács, \& Sherman, 2012; Kalocsai, 2009). Thus, it was natural for these participants to see interaction with fellow international students as the center of their English usage.

\section{Reports on Learning}

Each of the participants reported on learning some type of constructions, or as they were conceptualizing it, vocabulary and grammar, or they reported on developments in their ability to use English in some way, but there was variation in their responses. As would be expected, less proficient and less experienced students more frequently reported on learning, and highly proficient and more experienced students reported less on learning. For some of the participants, this was the first time they used English extensively, or they had not been using English recently, as is reflected in the comments from a German student in Excerpt $1^{4}$.

\footnotetext{
${ }^{4}$ Excerpts were edited for clarity, often times minimizing or leaving out the contributions of the interviewer where it was not necessary. This was done to make the examples more readable, but all efforts were made to preserve the original meaning and wording.
} 


\section{EduLingua 6/1 (2020)}

(1) Yeah, this [thinking about language] is every time a problem because I'm um not very used on it, here in Hungary it's the first time that I'm talking in English for more than one week, not even for more than one day $[\cdots]$.

This particular student's limited experience led him to be thinking extensively about language while using English, as he reported. Others noted they simply did not care much about English, or that they had had more extensive experience in ELF contexts or with native speakers. For example, in Excerpt 2, a German student reported that she believed she had learned a single word during her time in Prague.

(2) I don't think my English improves at all, I don't think I get more fluently because in Germany I also had to talk in English sometimes, and I don't think that I learned, so I didn't learn any new words, only once since it was burning in the kitchen in our dormitory and I tried to explain that they used the "fire extinguisher" so this was the new word. So, OK, I learned one more word since I'm here.

Thus, despite differences in proficiency and previous experience, all participants noted changes and development in their English on some level. Some participants had more to say and others less, which is also to be expected given the general questions that they were asked. Also, since learning might, as noted before, be happening at the most subtle levels, the effects themselves might be too subtle to be noticed. But, participants' reports on their use of learning strategies will tell more about the possibility of their learning, and I will turn to that next.

\section{Reports on Learning Strategies}

Due to limitations of space, I will focus on seven participants' data and four emergent strategies which are representative of the experiences of the larger group of 12 participants: paying attention to context, finding a relative expert, having an agenda, and learning independently.

\section{Strategy 1: Paying attention to context}

Due to the high context-dependency of ELF communication as higher-order language contact between speakers of varying proficiency and different similects (Mauranen, 2018), paying attention to context is a key strategy for both using ELF and learning. In previous research, students noted this highly specific nature of ELF interaction, one describing it as "It's like more like a liquid and it's actually created every time when some people meet" (Peckham, 2009b, p. 455). Variation is thus dependent on people and contexts, and users of ELF need to pay attention to this. Below, three different aspects of this strategy will be presented based on the features that the participants were attending to. 
First, the multilingual nature of ELF communication contexts was commented on by many participants. This can be seen in Extract 3, below, where a German student studying in Hungary presents the situation of choosing which language to speak.

(3) Sometimes we even try to use Hungarian because there are some students who don't know how to talk in English, they are not able to speak English. For example, Russian students, and they learn some German but not enough to communicate with us and so sometimes it's just the easiest way to talk in Hungarian [...] but, um it's hard, and I'm not one of the best ones, so, but it's too hard for me. There are some others who talk Italian, Spanish or something, you get to know each other, you ask yourself, you ask [...] the other um [...] just Hungarian which language he speaks and then you probably find one language that both [...] speak and then you communicate in that language.

In Extract 3, the student is describing the negotiation that goes on concerning which languages are available to communicate in and which they must or would like to use. The point is that before English can even be used, a decision must be made to use it rather than any of the other shared languages.

This is also shown in Extract 4 where another German student notes the wide variety of languages she uses, and also highlights, incidentally, that English is not her strongest language.

(4) Student: And so the last three years [...] um, well, I've, how do you say, they've passed, they've passed three years without just talking English and now it's really difficult because there's Hungarian and Spanish and German, and well, $O K$

Interviewer: So do you use four languages with the participants of the summer school, with the students?

Student: Yeah, yeah, I try. Yes, there's just one Spanish person, um but it's $O K$ and it's fun because for me it's really a relaxing just, well, be abling to express myself without, well, without any problems or, yes

The participants quoted above know though practice that ELF is used in a multilingual setting, which is different in this respect from a native speaker environment, where only one language, English, might be used. As Jenkins (2015) points out, current views see ELF in the context of multilingualism, noting that "English, while always in the (potential) mix, is now conceived as one among many other languages, one resource among many, available but not necessarily used, with ELF defined not merely by its variability but by its complexity and emergent nature" (p. 77).

As well as negotiation for which languages can be used, students report code switching in conversations with the knowledge that there are people involved in the interaction that might understand the code-switched segments. This is shown in Extract 
5, where a French Erasmus student reflects on the task of assembling the presentation which he just carried out with a Finnish student. In that interaction they were negotiating about the use of a different word than "famous".

(5) [That] is a French word and I know she can speak a very very few words in French, so I tried even if just to try, and that no she didn't get it, so "famous", but it's not really the same meaning, I would prefer to say "linked to reputation", or that I don't know the word, and I wanted her to understand something linked to reputation, but no, so OK, say "famous", less meaningful but say famous.

This type of codeswitching, or "micro-switching in ELF talk" is well documented in the ELF literature, and has a wide variety of functions (Motschenbacher, 2013, p. 62). To learn through interacting in ELF, one needs to clearly understand what the context is. Here it is always a multilingual context, and part of what is learned here are the strategies for negotiating that context and how to draw on collective linguistic resources, something which can be seen as an aspect of multicompetence from a usagebased perspective (Hall, Cheng, \& Carlson, 2006).

A second aspect of understanding the context is to recognize where a speaker is from, that is, their similect, and also their level of proficiency, two of the other variables which are at work in all ELF contexts. Most of the students were highly attuned to this dimension. In Extract 6, a German student discusses evaluating non-native speakers when she meets them.

(6) Interviewer: So when you speak with other non-natives you may have a sense you know of how good someone is or

Student: yeah, how good he is and where he might come from and whatnot [...] It's just, yeah it's automatically.

This evaluation of others' English is something that nearly all participants discussed. Here it is interesting to note that this student says that it happens "automatically" that their level of English is guessed at.

Third, what happens after this is that more proficient speakers often accommodate to those who are speaking differently or who are perceived to be at a lower level. This can be seen in Extract (7).

(7) Interviewer: Does [knowing their level] change the course of your talk to them?

Student: Yeah usually, what happens is just I start talking like normally like this and they either you see from their face that they're a bit like, uh what? what? what? or yeah so that's when you make, uh, when you kind of decide or make the decision to slow down, and change the kind of language that you speak or to continue (...) with a non-native speaker that is on a lower level I really have to think what I'm saying and how I'm saying it, it's it's 
you have to produce the speech in a different way and it's much more complicated.

This type of conversational adjustment has been noted in the ELF literature, for example in business ELF communication (Kankaanranta \& Louhiala-Salminen, 2010). Accommodation in this sense is a way of ensuring that communication can happen and that all voices can be heard. It is also a driver of learning, and has been shown to be relied on in ELF conversations. It can mean speaking like other speakers, that is, picking up their way of speaking, their vocabulary, pronunciations, mannerisms, etc., as a means to show belonging to a group, something which has been described extensively by Kalocsai in her study of Erasmus students (2014, p. 133). In this sense we can think of accommodation as an example of awareness of other speakers, and the adjustment of one's speech as learning. Here, participants are learning not just how to communicate, but what means can best be used to communicate in a specific situation.

The same Finnish student from a previous extract highlights the "let it pass" strategy (Firth, 1996), which is common in ELF conversations, where speakers let unclear parts of communication pass by on the assumption that if it is important, it will be returned to or elaborated on by the speaker. This strategy, used in a slightly different way, is mentioned below in Extract 8.

(8) Student: I remember I was a bit confused what he was talking about, and then thinking about what is he trying to say and tell me [...] and I still said, yeah yeah, because I think it was more to get along to get on, and I wanted to hear, and I often say yeah yeah yeah to get the, you often understand more when they, if I thought he would explain it a bit more.

Interviewer: So you didn't want to interrupt him because you thought it would become clear?

Student: Yeah, because we communicate with so many people with so many levels of English, so it's sometimes it's a bit frustrating to ask all the time I'm sorry what do you mean? So, what I've realized that it's easier to give them a bit time and let them to explain the thing, and the same way, if I try to explain something to someone else, it's easier to kind of, if they give you a bit time and a bit space to get your idea there.

Here the Finnish student is giving the other person the chance to continue explaining themselves, which is a strategy she uses based on an evaluation of the context. What this strategy does is give speakers the chance to reformulate their utterances to become clearer and more precise if necessary.

Thus, this first strategy involves evaluating the context, the possible languages which can be used in conversation and to which degree, and the presumed proficiency of other speakers and how they are using language. This evaluation leads to language choice, code switching, conversational strategies, and changes in one's own English through accommodation and adjustment. ELF communication is highly context 
dependent and knowledge of that context allows speakers to adjust and develop their language use appropriately in order to carry out tasks or become part of a group. As Mauranen explains, accommodation and "enhanced explication" through interaction leads to a "feedback loop" between language users, thus causing change in groups' and individuals' language (2018, p. 13-14).

\section{Strategy 2: Finding a relative expert}

The second strategy relates to the linguistic models that participants look to in ELF interaction. The assumption in the standard second language acquisition literature is that learners will be looking to native speaker models while learning through interaction and in study abroad contexts. But, a hallmark of ELF communication is that norms are local and are not necessarily based on native-speaker models. In the present research, participants reported on looking for a "relative expert" who could serve as a model, that is, someone who appears to be more proficient or experienced than them who they can accommodate to or from whom they can actively borrow words and phrases. Students who reported having less experience with English or saw themselves as lower proficiency were more likely to look for a relative expert from whom they could learn. In Excerpt 9, a German student speaks about choosing someone to follow in learning.

(9) I'm uh listen every time I talk to uh to someone who speaks good English, um I try to uh to learn the expressions [...] Yeah it depends um for example, she [referring to the person he carried out the presentation task with] is a very good speaker I think and yeah good pronunciation and so I try to learn from her, um I've got a [...] friend in the course it's a Korean guy, and uh he doesn't speak so good English and so um no I don't try, I don't try to learn from him.

This participant notes that he listens for new expressions and tries to learn them from other non-native speakers whom he sees as better speakers of English. No mention is made here or anywhere in the data that these people are more native-speaker like, but merely that they are better.

One French student spoke of finding a pronunciation model and noted that nonnative speakers are easier to understand, as seen in Excerpt 10.

(10) Um as usual when speaking with her boyfriend [who is Australian], uh, I'm in front of my lack of English, and it was easier the previous semester because I was with a Greek guy and it's easier when people have an accent, when with their rolled $r$ it's easier to listen to, like work or word [trilled r], work [with trilled $r$ ] is closer to French and it's hard when they speak too good English

This situation where it is easier to understand other non-native speakers is mentioned often in the ELF literature (see Peckham, Kalocsai, Kovács, \& Sherman, 2012) and was mentioned several times in the data. Moreover, the French student later goes on to say 
in Excerpt 11 that not only are non-native speakers easier to understand, but it is the non-native accent that he wants to emulate.

(11) When we met I try to catch some expression or way of pronunciation. At the beginning in September it was the first time when I was forced to use English, and it sounds like uh "good morning" [said with a French accent] [laughs] but [...] the Greek guy had a Greek accent but not so stressed I picked some way of speaking from him, and yeah, I try to pick up some expression of melody [...]. Hmm what did I learn? Mostly the pronunciation, uh, and after having spoken a long time with the Greek guy, in Greece they have a very different way of pronunciation, melody, and at the end I [...] realized I was speaking in a Greek English way [laughs].

The French student has chosen someone to learn pronunciation from whom he finds has a clear accent in English. This makes sense from the point of view that an important goal of ELF is effective communication and not meeting a native speaker model. In this case, the fact that the Greek student is a non-native speaker of English has actually made him a more attractive model or "expert" for the French student. What is at stake here is the multicompetence knowledge that makes a person an effective user of English as a lingua franca.

There is no reason to assume that there are groups of participants who either see themselves as "novices" and "experts". Indeed, there may be many things that can be learned from different types and levels of experts. Furthermore, a participant may be a learner in one situation and an expert in another. This is shown in Excerpt 12, also by the same French student, where he finds himself in the role of expert.

(12) Interviewer: What are the things you pay attention to when speaking to other non-native speakers? How does it depend on your partner, on the person you're speaking to?

Student: It depend mostly on his or her level of English, uh for example with the Kazakh girl [his current roommate] I don't speak so quickly and I yeah I try to keep a part of my French accent, she can get more of the words, and but yeah with native speakers or with good English speakers I just try to speak far away from French pronunciation.

Here he notes how he is changing his speech to be more understandable for the lowerlevel participant in interaction, and in this case, he is keeping his French accent, presumably using less of the Greek accent he mentioned earlier. He demonstrates that he can be both in the role of "expert" and learner or "novice".

Thus, by using the "finding a relative expert" strategy, students are showing that they are looking for models and goals among their ELF interactants and are potentially learning in this way. Certainly, they are employing this as a strategy for learning, whatever the outcome. While learning through interaction has been widely researched, what is interesting here is that the best communicators - not native speakers or 
classroom teachers - are seen as the goal setters and thus relative experts. This makes sense: if learning is happening here, participants are developing their knowledge of how to be multicompetent users of ELF.

\section{Strategy 3: Having an agenda}

A third learning strategy that participants reported on was to have an agenda for aspects of language that they want to learn. This "agenda" could be a specific list of items which they were on the lookout for in conversations, or a specific area of language which they were working on.

Excerpt 13 is from a German student who notes that he is looking for "grammar" in conversations.

(13) Student: Um yeah it's um how to use of, in, on, and so on, and so like it depends ON, yeah I'm trying to learn this, uh yeah and the tense like uh have been and so on, when you use it and when you use I was and

Interviewer: So you're sort of listening for grammar and...

Student: Grammar, yeah and I think my vocabulary is not bad and I can understand English language better than I can speak it, so it's not a great problem.

The student in Excerpt 13 notes that it is not vocabulary he is looking for and looking to learn in conversations, but grammar, in this case prepositions, phrasal verbs, and verb tenses. When he speaks of "grammar", though, he is talking about looking for certain combinations of words, as would be expected from a usage-based, constructivist position on grammar where learning happens though the development of exemplars and not through learning "rules". This same student also notes that he is listening for pronunciation, but of particular words.

(14) I've got these words I'm listening to the pronunciation like "rather" I wasn't sure about like "rether" or something like that so I got these words I always try to find in in discussions or something like that and conversations and when I hear it I think oh it's "rather".

Again, this participant is focusing his attention on and looking for particular words in conversation that he has a question about, and, in doing so, he is learning in an ELF context, in conversation with other non-native speakers of English. Furthermore, he is being highly selective in what he is looking for.

Other participants focused on vocabulary. In Excerpt 15, a German student describes how communicating in English highlights her lack of vocabulary in certain areas, and this leads her to focus on word learning.

(15) Well in general, um, if there's a conversation, um and it's a certain topic and I miss the vocabulary because it's really, well my vocabulary is so 
basic that many times I must think, Oh, how is it called? Well then I just can't express what I want to say, and um well the grammar is not that big problem um because the others can understand me or able to understand me, but many times I just feel uncomfortable, I just think OK you have to improve and just like this, and that's what I'm going to do...

Participants noted that it is the experience of using English actively for the first time which pointed to areas where they lacked vocabulary for the situation. Excerpt 15 highlights the communicative power of lexical items in conversation. The participant notes that concerning grammar, other interactants are able to understand her, but her lack of words makes her feel "uncomfortable", and she has a plan to address this situation.

Similarly, in Excerpt 16, another student notes how it is the frequency of the experience of realizing that she does not know a word that leads her to learn it.

(16) So if I'm telling a story and I need a word and it doesn't come to mind and if I look for this word several times or if I'm missing this word several times then I look it up at home, then I really need to look it up. But if I'm only missing it once and can explain it with other words, then I'm too lazy or I forget about this.

Again, in this case and the previous one, it is the event of communicating in ELF which leads the students to expand their vocabulary. That is, their need arises directly from the communicative context they are engaged in.

Students also noted more complex relationships between language and communicative context as is illustrated in Excerpt 17, where a student discusses the pragmatics of how to respond appropriately in particular situations.

(17) Interviewer: Do you feel like you've learned how to communicate between people, between non-native speakers, let's say?

Student: Yeah, I think so. Because the most problematic thing for me at the moment is that, in every country I think - I can only speak for Germany there is some kind of code how to introduce yourself, how to introduce others, how to say things in a polite way. So, for example if I want to come up with things like "I do not like what you did there and there" or "I would appreciate it if you did it like this and this" so if I want to say something like that I know very precisely how to phrase it in German. I can get the message through on the one hand, but on the other hand I can stay polite. And this is one thing which is really hard for me at the moment because I have the feeling that I'm either too polite or I'm too rough, so this is a problem, but I think I begin to learn how I can phrase these things in English so that people would not be [...].

Interviewer: And do you learn it from them? 
Student: I think I learn because I see their reactions, so I can see like OK this was too fierce or they do not understand this word or this was maybe not the right word to say, you would say it in German but for them it sounds very impolite for example because it's often the case because, yeah, maybe Germans have a tendency to say things as the think, and so I learn this but, this is like an intercultural thing. This doesn't really have to do with, it has to do with language but still Italians see it differently from Finnish people, Finnish people see it differently from American people, so it's like I always have to get to know the person I'm talking to and then I can react, but I think this is one of the best ways to learn language because you can react to everybody and then you have to choose the register of language you will employ at that time.

This long excerpt shows that the student has identified a particular issue in communication, and then uses ELF interaction to develop her knowledge. She is aware that her first-language pragmatic competence may not necessarily transfer to this context and is on the lookout for how she is being received. Also, she is aware that her interlocutors are not adopting Anglo-American pragmatic norms, but are using English as a vehicular language, and not as a means of cultural identification. She knows that speakers from different linguacultural backgrounds may have different pragmatic considerations that color their expectations in English. This type of linguistic knowledge is highly context dependent and generated and learned through use. Here it is also important to note that what the student is finding out is not necessarily how Italians or Finns behave linguistically, but how in the context of ELF communication speakers from various linguistic backgrounds carry out communication. The student approaches it as a linguist would, carrying out an analysis and testing hypotheses, and as such she is in an excellent position to clearly understand and learn how ELF communication is organized.

In sum, these examples show that these learners approach ELF interaction with the intent to learn various aspects of the language, from vocabulary and grammar, to accent and pragmatics. The ELF interaction they have opens up the opportunity for learning these aspects of language, no matter what their previous experience is. One student may have an agenda to learn which prepositions are associated with which verbs, while another is examining how subtle changes in her language affect the responses of those around her. Overall, what this strategy allows these participants to do is to focus their attention on elements of the interaction which are relevant for their own personal development. In this sense, having an agenda helps drive what can be considered explicit goal-driven learning. That is, rather than simply experiencing incidental and even implicit learning which may naturally accompany language use, these participants are acting like learners who have clear language development goals that they want to achieve. 


\section{Strategy 4: Learning independently}

The final strategy presented refers to students deciding to work on their own, outside of interaction with other speakers, to develop their language skills. It should be noted that this work was done outside of any kind of classes or coursework that they might be involved in. Whereas the previous strategy may have led to work outside of the conversational context, the learning independently strategy refers to what participants actually did on their own.

First, some students noted that realizing they needed conversational English skills, they turned to British and American films and television to either make a transition from the language classroom to actual language use, or to balance out their recent approach to focusing on academic English, as is shown in Excerpt 18.

(18) Here because I have a fast internet connection I can watch like news or $T V$ shows and so on, and this is like I can learn everyday language, and this is much more practicable in the situations I'm in here with the other Erasmus students [...]. You don't have to say or employ this academic English because this is complete nonsense in here so these TV shows they really help me to get to know every-day English language. And the others do the same.

In this excerpt the student realizes that to fit in better in the group with English she needs to learn more colloquial English, and so turns to television. It is interesting to note that whether or not watching English and American TV will help her become a better ELF communicator, she has realized that the context of ELF communication requires something other than her previous, academic approach to English. The goal here is to fit in better with the group.

Using a different approach, the participant in Excerpt 19 describes practicing conversations so that he can be prepared to speak when he meets up with his friends.

(19) Student: Uh, yeah, when I'm when I'm alone like on my way from school to my flat um I'm imagine I'm tell I don't know an English or Korean guy, uh something in English, I want to tell him about my day or something like that, and then I'm I want to translate directly so I have the German sentence and I won't describe it just uh say it directly and when a word is missing I'm trying to look it up in the dictionary. Yeah, those are my BIG strategies.

Interviewer: That's great. So you're actually telling stories with yourself, actually role playing

Student: Yeah yeah role playing [...]

Thus, in this situation the participant is rehearsing what it is he might want to say, and then looking up words in the dictionary when he realizes what he does not know. Again, 
it is the immediate context of communication which is motivating the student to take this action.

This student also describes how interacting with others highlighted his need for basic vocabulary and so this led him to preemptively look up words that he thought he was going to need, as is seen in Excerpt 20.

(20) Student: I'm living in a flat and in this flat we [...] a Mexican guy, very comfortable, yeah and in the flat I'm living with a Finnish girl and so you have to do you have to tell everything in English and um so I'm looking up for words like for water basin and, yeah and so on.

Interviewer: So it sounds like you have a strategy of if you want to say something you can, you need it a lot, like water basin you look it up then

Student: Yeah, I walked through the kitchen and yeah I think it's uh better than um than describe everything, you know you don't know the word for water basin and you only say the the thing that water, uh yeah

In both of these cases this student is actively preparing for using English based on his experience of what he needs to communicate about. This is happening independently, outside of speaking with others. The above excerpt shows that he knows the communication strategy of circumlocution but decides to use the learning strategy of noting and looking up the word.

Another student discussed how she takes notes on things she says and is unsure of, and marks them for study later. This is seen in Excerpt 21.

(21) Student: Well, often there's a situation then I just think OK, then I'm not sure about the use, um of, I don't know any grammar, yes and those are the situations when I think OK, you have to do this and this and this and, um, sometimes I even take notes, so that I can write, OK you have to do that and that one, and then, $O K$

Interviewer: What kind of notes?

Student: Well, just about, well, for example, I don't know, something easy like "if clauses", because, I don't know.

The participant in Excerpt 21 is using the ELF communication context to note instances of grammar that she imagines that she should know more about to be a more effective communicator. While there is no report from the student concerning whether or not she uses this information to test out a hypothesis in conversation later, it is still possible to see that it is this conversational context which has given rise to her question.

All of these examples of the learning independently strategy show that the participants in these programs were led by their experience to learn more about the language, either words or styles of speaking. This learning inspired by ELF interaction allows for three potential effects. First, this independent work gives students an 
opportunity for further encountering new language which they can bring to ELF interaction - for example, new words can be looked up for which there will likely be a need. Second, working on their own gives these participants the opportunity to consolidate those things which they are learning and experiencing. This consolidation phase of learning is also an important element of organized, classroom-based learning, but can be applied here. After "improvising" through using language, consolidation allows speakers to "prepare for language production" and "go beyond the basic presentation of their message" (Willis, 2003, p. 22). And third, independent learning allows for the possibility of rehearsal, as was seen in Excerpt 19. This kind of task preplanning and rehearsal have been shown to have a positive impact in fluency and accuracy (Ellis, 2009), and thus similar to consolidation this can lead to learning. Furthermore, up to date with current thinking about language instruction, these participants are focusing on form in communicative context (Lightbown \& Spada, 2013), and working independently gives these participants the chance to attend to the connections without the immediate attention-draining pressure of communication at that moment.

\section{General Discussion}

Overall, then, concerning learning through ELF communication, evidence has been found for both research questions raised in this paper. All students reported on learning at least something in their recent experience. More importantly, across the group of students a variety of learner strategies were reported on. These strategies meet the definition of strategies of being thoughts and actions taken to accomplish tasks and develop long- or short-term language proficiency, as discussed above. Indeed, as was noted, with study-abroad students in general, language itself is a central concern, and this is also evidenced specifically by the present participants' willingness and ability to discuss their own language use and learning in great detail. Thus, there is indirect evidence that learning is happening through their reports of learning and use of learning strategies. On a group level, then, this suggests that using English as a Lingua franca is a context where speakers not only are communicating messages, practicing what they have already learned, and interacting using English in general, but that they are indeed learning language. Speakers are taking personal initiative to focus their attention on form and meaning for the purpose of developing their language competence on levels ranging from phonology to pragmatics. In short, this is a site for language learning, and given the prevalence of opportunities for using ELF, it may be for some the preeminent opportunity for language learning.

One objection to this conclusion could be that indirect reports of learning are not evidence of learning. Indeed, this is true, but there are three lines of thinking which support a connection between learning and the participant reports. First, learning through interaction is seen in the field of second language acquisition as one of the most 
important ways in which language learning happens both inside and outside the classroom, and has been the subject of a tremendous amount of research which suggests that conversational interaction is an important venue for learning (Mackey, 2007a). Second, there is precedent in the second language literature to look for secondary, indirect indicators of learning which do not depend on the measurement of learning outcomes. The presence of markers of "negotiation for meaning" has long been used as an indicator of the potential of learning in that these moves focus the attention of speakers on specific aspects of language to be learned (Mackey, 2007b). And third, in research on learning strategies work has been done from the early work on the "good language learner" (Naiman, Fröhlich, Stern, \& Todesco, 1995) to the present which suggests that there is indeed a connection between the use of language learning strategies and learning. Thus, although it was not possible to measure actual learning in the present study, there is a likelihood that it is happening in this situation.

A second potential objection centers on focusing on language learning itself in ELF interaction. The objection here is that participants in ELF communication are not learners of English using an imperfect version of native speaker English which they will forever be short of mastering, but that they are users of ELF in a space where native speaker English, standard English, and "real English" are not valid norms. That is, to discuss learning is seen to suggest that the participants in ELF communication are somehow deficient and to impose an English as a native language viewpoint. But, it needs to be emphasized that the definition of ELF as higher-order language contact between similects sets the stage for the competence being unique which is developed and expressed there, and that participants in the present study see themselves as learning through ELF interaction in that very context. Moreover, considering language competence as context-dependent and usage-based multicompetene (Hall, Cheng, \& Carlson, 2006), it is apparent that ELF communication is indeed a space where language learning must be happening - it is where form, meaning, and social context meet, and in fact this, for some speakers of English, may be the first and perhaps only context where they are actually using English, as was reported by some of our speakers. As such, it is of interest to investigate learning in this context - with the caveat that what is developing may not reflect, or need not reflect, idealized native speaker competence.

Thus, there is good reason to believe that there is learning of form and meaning connections happening in the context of ELF communication.

\section{Conclusion}

There are limitations to this current study due to its small-scale nature and inability to precisely measure that learning has happened. Nevertheless, there are some possible implications for the teaching of English. First, it is worth noting that English language learning continues after speakers have finished foreign language classes in secondary school. It is not the case that learners only become users outside of the classroom. This 
study shows that they can remain active learners. Second, one of the most likely settings for using and also continuing to develop competence in English is going to be using English as a lingua franca, and thus in order to prepare students for this, they need to be aware of the particular nature of this setting, something which is noted as lacking in English as a foreign language materials ( $\mathrm{Yu}, 2015$, p. 36). Third, it is important to note that the skills and strategies which are useful in learning in lingua franca contexts are applicable to all contexts if indeed the goal is developing the multicompetence which allows speakers to navigate varying linguistic situations. The skills that are needed involve making sense of language - that is, "languaging", in Larsen-Freeman's view (2003) - and not simply adherence to prescribed norms based on idealized speakers. Speakers develop over a lifetime of experience by responding to new contexts, languages and modes of communication, and it appears that much this experience for many English speakers will be happening in ELF contexts.

As a final note, it should be mentioned that research for this present paper was carried out more than ten years ago, but the use of ELF and the study of this phenomenon has grown considerably during that time, making considerations of how English is used and taught even more important. Furthermore, with the United Kingdom having left the European Union, it is now the case that English, commonly used in the public and private spheres in the EU, is no longer the official language of any member state. This can provide a new context for the further development of use of ELF and raise more questions about the teaching and learning of English.

\section{References}

Bybee, J. (2010). Language, usage and cognition. Cambridge: Cambridge University Press.

Cogo, A., \& Jenkins, J. (2010). English as a lingua franca in Europe: A mismatch between policy and practice. European Journal of Language Policy, 2(2), 271294. https://doi.org/10.3828/ejlp.2010.16

Cohen, A. D., \& Henry, A. (2020). Focus on the learner: Styles, strategies and motivation. In N. Schmitt, \& M. P. Rodgers, An introduction to linguistics, 3rd edition (pp. 165-189). London: Routledge.

De Jong, N., \& Perfetti, C. A. (2011). Fluency training in the ESL classroom: An experimental study of fluency development and proceduralization. Language Learning, 61(2), 533-568. https://doi.org/10.1111/j.1467-9922.2010.00620.x

Directorate-General for Education, Youth, Sport and Culture. (2020). Annex Erasmus + Annual Report 2019. Luxembourg: European Commission. 
Ellis, N., \& Larsen-Freeman, D. (2006). Language emergence: Implications for applied linguistics - Introduction to the special issue. Applied Linguistics, 27(4), 558-589. https://doi.org/10.1093/applin/am1028

Ellis, R. (2009). The differential effects of three types of task planning on the fluency, complexity and accuracy in L2 oral production. Applied Linguistics, 30(4), 474509. https://doi.org/10.1093/applin/amp042

Firth, A. (1996). The discursive accomplishment of normality: On conversation analysis and 'lingua franca' English. Journal of Pragmatics, 26, 237-259. https://doi.org/10.1016/0378-2166(96)00014-8

Goldberg, A. E. (2006). Constructions at work: The nature of generalization in language. Oxford: Oxford University Press.

Graddol, D. (2006). English Next. London: The British Council.

Hall, J. K., Cheng, A., \& Carlson, M. T. (2006). Reconceptualizing multicompetence as a theory of language knowledge. Applied Linguistics, 27(2), 220-240. https://doi.org/10.1093/applin/am1013

Hynninen, N. (2016). Language regulation in English as a lingua franca. Berlin: De Gruyter.

Jackson, D. O. (2001). Language-related episodes. ELT Journal, 55(3), 298-299. https://doi.org/10.1093/elt/55.3.298

Jenkins, J. (2007). English as a lingua franca: Attitude and identity. Oxford: Oxford University Press.

Jenkins, J. (2015). Repositioning English and multilingualism in English as a lingua franca. Englishes in Practice, 2(3), 49-85. https://doi.org/10.1515/eip-2015-0003

Jenkins, J., Cogo, A., \& Dewey, M. (2011). Review of developments in research into English as a lingua franca. Language Teaching, 44(3), 281-315. https://doi.org/10.1017/s0261444811000115

Jenkins, J., Cogo, A., Peckham, D., Tamah, Sherman, T., \& Sieglová, D. (2010). Learning, use and perceptions of English as a lingua franca communication in European contexts. LINEE WP7a Research Report.

Kalocsai, K. (2009). Erasmus exchange students: A behind-the-scenes view into an ELF community of practice. Apples - Journal of Applied Language Studies, 3(1), 2549.

Kalocsai, K. (2014). Communities of practice and English as a lingua franca: A study of Erasmus students in a central-European context. Berlin: De Gruyter Mouton. 
Kankaanranta, A., \& Louhiala-Salminen, L. (2010). "English? - Oh, it's just work!": A study of BELF users' perceptions. English for Specific Purposes, 29, 204-209. https://doi.org/10.1016/j.esp.2009.06.004

Larsen-Freeman, D. (2003). Teaching Language: From grammar to grammaring. Boston: Thomson Heinle.

Lightbown, P. M., \& Spada, N. (2013). How languages are learned. Oxford: Oxford University Press.

Mackey, A. (2007a). Conversational interaction in second language acquisition. Oxford: Oxford University Press.

Mackey, A. (2007b). Interaction as practice. In R. M. DeKeyser (Ed.), Practice in a second language: Perspectives from applied linguistics and cognitive psychology (pp. 85-110). Cambridge: Cambridge University Press.

Mauranen, A. (2018). Conceptualizing ELF. In J. Jenkins, W. Baker, \& M. Dewey (Eds.), The Routledge handbook of English as a lingua franca (pp. 7-24). London: Routledge.

Motschenbacher, H. (2013). New perspectives on English as a European lingua franca. Amsterdam: John Benjamins Publishing Company.

Naiman, N., Fröhlich, M., Stern, H., \& Todesco, A. (1995). The good language learner. Clevedon: Multilingual Matters.

OECD. (2020). International student mobility (indicator). Retrieved 2020 December, from https://doi.org/10.1787/4bcf6fc3-en

Oxford, R. L. (1990). Language learning strategies: What every teacher should know. Boston, MA: Heinle.

Oxford, R. L. (2017). Teaching and researching language learning strategies, 2nd edition. London: Routledge.

Pawlak, M., \& Oxford, R. L. (2018). Conclusion: The future of research into language learning strategies. Studies in Second Language Learning and Teaching, 8(2), 525-535. https://doi.org/10.14746/ssllt.2018.8.2.15

Peckham, D. W. (2009a). Informal and incidental learning in ELF contexts. The second conference of English as a lingua franca, University of Southampton, April 6-8.

Peckham, D. W. (2009b). The names of English: Non-native insights into English as a lingua franca. In A. Borbély, I. Vanconé Kremmer \& H. Hattyár (Eds.), Nyelvideológiák, attitüdök és sztereotípiák: 15. Élőnyelvi konferencia (pp. 454457). Budapest: Tinta Könyvkiadó.

Peckham, D. W., Kalocsai, K., Kovács, E., \& Sherman, T. (2012). English and multilingualism, or English only in a multilingual Europe? In P. Struder, \& I. 
Werlen (Eds.), Linguistic diversity in Europe (pp. 179-201). Berlin: De Gruyter Mouton.

Ranta, E. (2018). Grammar in ELF. In J. Jenkins, W. Baker, \& M. Dewey (Eds.), The Routledge handbook of English as a lingua franca (pp. 244-254). London: Routledge.

Seidlhofer, B. (2000). Mind the gap: English as a mother tongue vs. English as a lingua franca. Vienna English Working Papers, 9(1), 51-69.

Smit, U. (2010). English as a lingua franca in higher education: A longitudinal study of classroom discourse. Berlin: De Gruyter Mouton.

Tseng, W., Dörnyei, Z., \& Schmitt, N. (2006). A new approach to assessing strategic learning: The case of self-regulation in vocabulary acquisition. Applied Linguistics, 27(1), 78-102. https://doi.org/10.1093/applin/ami046

Wächter, B., \& Maiworm, F. (2014). English-taught programmes in European higher education: The state of play in 2014. Bonn: Lemmens Medien GmbH.

Widdowson, H. (1994). The ownership of English. TESOL Quarterly, 28, 377-389. https://doi.org/10.2307/3587438

Willis, D. (2003). Rules, patterns and words. Cambridge: Cambridge University Press.

Yu, M. H. (2015). Developing critical classroom practice for ELF communication: A Taiwanese case study of ELT materials evaluation. In H. Bowles, \& A. Cogo (Eds.), International perspectives on English as a lingua franca: Pedagogical insights (pp. 35-54). New York: Palgrave Macmillan. 